\title{
SIMULASI DAN ANALISIS JARINGAN METRO ETHERNET KOTA BANDUNG TAHUN 2028 MENGGUNAKAN OPNET MODELER
}

\author{
Arif Nur Hidayat*), Sukiswo, Ajub Ajulian Zahra \\ Departemen Teknik Elektro, Universitas Diponegoro \\ J1. Prof. Sudharto, SH, Kampus UNDIP Tembalang, Semarang 50275, Indonesia \\ ${ }^{*}$ E-mail: arifnurhidayat22@gmail.com
}

\begin{abstract}
Abstrak
Sebagai salah satu kota metropolitan, jumlah pengguna perangkat telekomunikasi kota Bandung dipastikan besar. Seiring bertambahnya jumlah penduduk, maka trafik data yang dibangkitkan juga bertambah. Sehingga, diperlukan jaringan yang mampu melayaninya. Metro ethernet merupakan salah satu jaringan yang cukup memadai untuk melayani trafik data telekomunikasi saat ini. Penelitian ini merancang pemodelan dan analisis jaringan metro ethernet. Pemodelan jaringan metro ethernet menggunakan perangkat lunak OPNET Modeler. Analisis performansi jaringan dilakukan dengan cara mengukur metriks QoS (Quality of Service) berdasarkan standar PT. Telekomunikasi Indonesia, Tbk dan ITU-T. Metriks performansi jaringan yang digunakan antara lain round trip delay (RTD), jitter, packet loss, dan utilisasi link. Hasil pengukuran menunjukkan bahwa nilai rata-rata RTD jaringan sebesar 0,3542 ms, rata-rata nilai jitter jaringan sebesar 0,2159 ms, dan rata-rata packet loss jaringan sebesar 0,000585\%. Nilai utilisasi link tertinggi terdapat pada link LBG $\leftrightarrow$ RJW sebesar 52,9631\%. Sedangkan, nilai utilisasi link terendah terdapat pada link UBR $\leftrightarrow$ CJA sebesar $29,7614 \%$. Skema dynamic routing menggunakan protokol OSPF diterapkan pada jaringan. Rata-rata waktu konvergensi jaringan dari variasi tiga skenario sebesar $15 \mathrm{~s}$.
\end{abstract}

Kata Kunci: Metro ethernet, performansi jaringan, round trip delay, jitter, packet loss, utilisasi link, routing, OSPF

\begin{abstract}
As one of the metropolitan cities, number of users telecommunication equipment in Bandung is certainly large. As the population increases, the data traffic generated also increases. So, it is necessary to have a network capable of serving it. Metro Ethernet is one of the networks that is sufficient enough to serve telecommunications data traffic at this time. This final project designs modeling and performance analysis of metro ethernet networks. Metro ethernet network modelling use OPNET Modeler software. Network performance will be analyze with measuring QoS (Quality of Service) metriks based on PT. Telekomunikasi Indonesia, Tbk and ITU-T standard. Network performance metrics used namely round trip delay (RTD), jitter, packet loss, and link utilization. The measurement results show that the average value of the network RTD is $0.3542 \mathrm{~ms}$, the average network jitter value is $0.2159 \mathrm{~ms}$, and the average network packet loss is $0,000585 \%$. The highest link utilization value is found in the LBG $\leftrightarrow$ RJW link of $52.9631 \%$. Meanwhile, the lowest link utilization value is found in UBR $\leftrightarrow$ CJA link of $29.7614 \%$. Dynamic routing schemes using the OSPF protocol are applied to the network. The average time of network convergence from the three scenario variations is $15 \mathrm{~s}$.
\end{abstract}

Keywords: Metro ethernet, performansi jaringan, round trip delay, jitter, packet loss, link utilization, routing, OSPF

\section{Pendahuluan}

Menurut data Badan Pusat Statistik Kota Bandung, jumlah penduduk Kota Bandung tahun 2016 adalah 2.490.622 jiwa dengan laju pertumbuhan penduduk $0,37 \%$ per tahun [1]. Sebagai kota metropolitan, tentu kota Bandung erat kaitannya dengan dengan penggunaan perangkat telekomunikasi. Dengan bertambahnya penduduk dari tahun ke tahun, maka aliran data yang dibangkitkan dari penggunaan perangkat telekomunikasi juga bertambah. Sehingga, diperlukan jaringan yang mampu untuk melayaninya.
Metro Ethernet merupakan Next Generation Network (NGN), salah satu jaringan yang cukup memadai untuk dapat melayani kebutuhan telekomunikasi saat ini. Metro ethernet merupakan teknologi berbasis wired network dengan memanfaatkan serat optik sebagai media transmisinya. Faktor-faktor yang memengaruhi kinerja jaringan metro ethernet antara lain topologi jaringan dan link.

Penelitian terdahulu yang berkaitan dengan analisis jaringan metro ethernet antara lain, Satya Yoga Pratama [2] melakukan analisis jaringan metro ethernet regional 
Jawa Tengah dengan metriks performansi round trip delay, jitter, dan packet loss, serta melakukan peramalan trafik setahun mendatang. Apit Tri Susilo [3] menjelaskan secara luas mengenai perbandingan antara jaringan metro ethernet dengan jaringan leased line. Devi Tiarani P, dkk [4] membahas tentang performansi jaringan DWDM ring DIY-Semarang-Surakarta dan meramalkan bandwidth link untuk tahun 2030.

Pada penelitian ini akan memodelkan jaringan metro ethernet dengan studi kasus kota Bandung untuk keperluan 10 tahun mendatang. Jaringan disimulasikan sesuai dengan kondisi real serta sesuai dengan data-data yang didapat. Topologi jaringan akan dimodelkan dan disimulasikan dengan menggunakan perangkat lunak OPNET Modeler. Analisis performansi jaringan metro ethernet pada penelitian ini menggunakan metriks QoS (Quality of Service), antara lain meliputi round trip delay, jitter, packet loss, dan utilisasi link.

\section{Metode}

\subsection{Diagram Blok Sistem}

Sistem yang dirancang merupakan sebuah simulasi jaringan metro ethernet untuk studi kasus kota Bandung. Perancangan simulasi jaringan metro ethernet ini dibuat berdasarkan alur kerja dalam penggunaan simulator OPNET Modeler. Sedangkan keseluruhan perancangan simulasi ini dibuat berdasarkan diagram alir. Diagram alir simulasi berfungsi untuk menentukan alur pemikiran dalam perancangan simulasi dalam penelitian ini. Diagram alir perancangan dapat dilihat pada Gambar 1 .

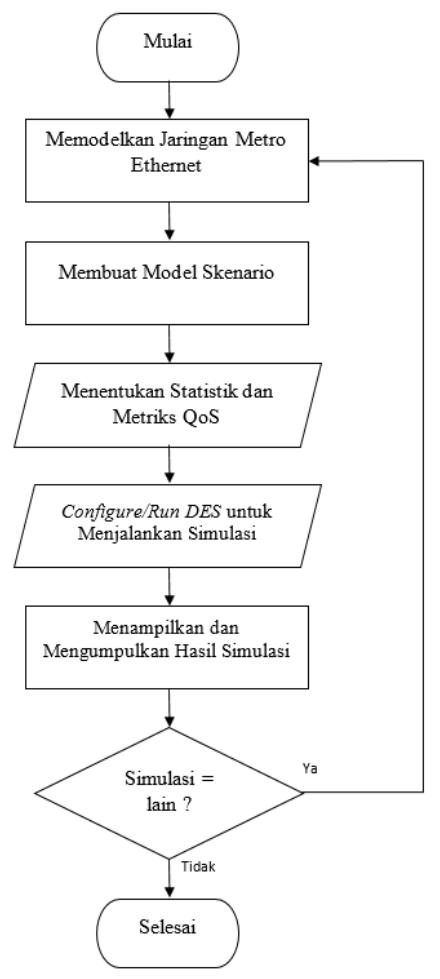

Gambar 1. Diagram alir simulasi

\subsection{Pemodelan Jaringan}

Pembuatan simulasi ini menggunakan beberapa buah objek yang berbeda sesuai fungsi pada jaringan. Pada dasarnya, fungsi dari perangkat metro ethernet adalah sebagai switching disertai fungsi tambahan routing untuk meneruskan dan mentransmisikan paket data yang telah dibangkitkan. Node Huawei Quidway S7803 berfungsi sebagai perangkat metro ethernet (router switch) dan objek ethernet_server_adv berfungsi sebagai perangkat untuk mengasumsikan pembangkitan trafik jaringan. Sementara untuk media transmisi sebagai penghubung antar node router menggunakan 100Gbps_ethernet_adv dan 40Gbps_ethernet_adv. Sedangkan, media transmisi antara router dengan ethernet_server_adv menggunakan 10Gbps_ethernet_adv. Media transmisi disesuaikan dengan konfigurasi standar serat optik yang berkaitan. Alur kerja dalam membuat model jaringan dapat dilihat pada Gambar 2.

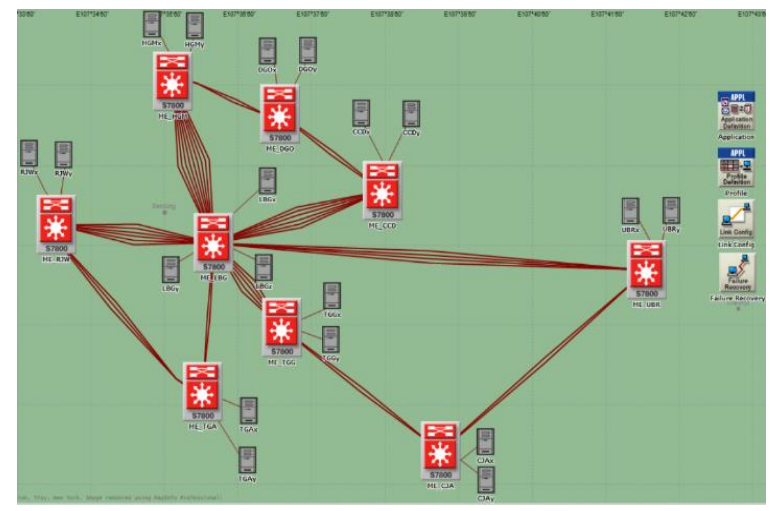

Gambar 2 Tampilan topologi jaringan metro ethernet kota Bandung pada OPNET Modeler

\subsection{Metriks Performansi Jaringan}

Tabel 1. Standarisasi metriks performansi jaringan

\begin{tabular}{ccc}
\hline Metriks & Std PT. Telkom & Std ITU-T \\
\hline RTD & $12 \mathrm{msec}$ & $<5 \mathrm{msec}$ \\
Jitter & $10 \mathrm{msec}$ & $<1 \mathrm{msec}$ \\
Packet Loss & $0,20 \%$ & $<0,001 \%$ \\
\hline
\end{tabular}

Tabel 1 menunjukkan standarisasi metriks performansi jaringan yang diberlakukan PT. Telekomunikasi Indonesia, Tbk [5] dan ITU-T [6]. Metriks performansi jaringan merupakan parameter yang digunakan sebagai tolak ukur performansi suatu jaringan ataupun link terhadap trafik yang dibebankan. Standarisasi metriks tersebut secara umum dikeluarkan oleh ITU-T (International Telecommunication Union Telecommunication Standardization Sector). PT. Telekomunikasi Indonesia, Tbk mengeluarkan standar khusus untuk round trip delay, jitter, dan packet loss. Standar ini dibuat berdasarkan kebijakan dan pertimbangan yang telah dilakukan. 


\subsubsection{Round Trip Delay (RTD)}

Round trip delay (RTD), merupakan penjumlahan dari dua nilai delay. Pada penelitian ini, RTD adalah penjumlahan dari delay paket data dan delay paket ACK dimana paket ACK diasumsikan memiliki ukuran paket sebesar 40 bytes[7]. Analisis jaringan untuk delay antrian dalam node yang terukur dalam delay proses dari delay total menggunakan model antrian tunggal (single quеие). Pengukuran antrian tunggal dilakukan berdasarkan antrian point-to-point antar node dan bukan antrian keseluruhan jaringan (queueing network). Untuk mencari RTD, dapat dihitung dengan Persamaan (1).

$$
R T D=T_{\text {Data }}+T_{A C K}
$$

Keterangan :

$\begin{array}{lll}\mathrm{RTD} & = & \text { Round Trip Delay }(\mathrm{s}) \\ \mathrm{T}_{\text {Data }}= & \text { Delay } \text { paket data }(\mathrm{s}) \\ \mathrm{T}_{\mathrm{ACK}}= & \text { Delay paket ACK }(\mathrm{s})\end{array}$

\subsubsection{Jitter}

Jitter dapat didefinisikan sebagai total variasi delay antara blok-blok informasi yang berurutan. Besarnya nilai jitter akan sangat dipengaruhi oleh variasi beban trafik yang ada dalam jaringan hingga berpeluang menimbulkan tumbukan antar paket (collision). Besarnya nilai jitter menandakan performansi link pada jaringan tersebut buruk, sehingga nilai jitter harus dijaga seminimal mungkin untuk mendapatkan performansi link yang baik dan handal. Pada OPNET Modeler, jitter disebut juga total variasi end-to-end delay dan untuk mengukurnya dapat menggunakan Persamaan 2.

$\operatorname{Jitter}(s)=\sqrt{(\text { delay yang terjadi }- \text { rerata delay })^{2}}$

\subsubsection{Packet Loss}

Packet Loss didefinisikan sebagai kegagalan transmisi paket data untuk mencapai tujuannya. Pada implementasi jaringan IP (termasuk metro ethernet), nilai packet loss ini diharapkan mempunyai nilai yang sekecil mungkin. Pengukuran packet loss dapat menggunakan Persamaan 3.

$$
\text { Packet Loss }=\frac{P_{S}-P_{r}}{P_{S}} \times 100 \%
$$

Keterangan :

$P s=$ packet sent $=$ paket yang dikirim (bits)

$\operatorname{Pr}=$ packet receiver $=$ paket yang diterima (bit)

\subsubsection{Utilisasi Link}

Utilisasi link merupakan rasio antara trafik jaringan saat ini dan trafik maksimum yang dapat ditangani oleh link. Utilisasi link menunjukkan penggunaan bandwidth dalam jaringan. Sementara utilisasi link yang tinggi menunjukkan jaringan dalam keadaan sibuk (busy), utilisasi jaringan yang rendah menunjukkan jaringan sedang kurang aktif. Ketika utilisasi link melebihi ambang batas kondisi normal, hal ini akan menyebabkan kecepatan transmisi rendah, keterlambatan permintaan dan sebagainya [8].

\subsection{Routing}

Routing atau perutean merupakan proses dimana paket dibawa dari satu lokasi ke lokasi lainnya. Contoh nyata sesuatu yang membutuhkan perutean adalah surat, panggilan telepon, perjalanan kereta api, dan lain sebagainya. Pada suatu jaringan telekomunikasi, router adalah perangkat yang digunakan untuk merutekan trafik jaringan [9]. Pada suatu sistem jaringan komputer, router mempelajari informasi routing dari sumber-sumber routing yang terletak di dalam tabel perutean (routing table). Router akan berpedoman pada tabel ini untuk menyatakan port mana yang digunakan mengirim paketpaket yang akan ditujukan.

\subsubsection{Open Shortest Path First (OSPF)}

Open Shortest Path First (OSPF) merupakan routing protocol link state dan digunakan untuk menghubungkan router yang berada dalam satu Autonomous System (AS). Sehingga routing protocol ini termasuk juga katagori Interior Gateway Protocol (IGP) [10]. OSPF bekerja dengan sebuah algoritma yang disebut algoritma Djikstra. Sebuah pohon jalur terpendek (shortest path tree) akan dibangun, kemudian routing table akan diisi dengan jalurjalur terbaik yang dihasilkan dari pohon tersebut [11].

\subsubsection{Waktu Konvergensi}

Waktu konvergensi merupakan bagian dari proses update routing table. Ketika terjadi link gagal atau terjadi perubahan rute, informasi terbaru dikirim ke seluruh jaringan yang menggambarkan perubahan dalam topologi jaringan. Setiap router kemudian menjalankan algoritma routing, melakukan perhitungan ulang, dan membangun routing table baru. Konvergensi merupakan proses routing dinamis, dimana update routing table terjadi secara otomatis.

\section{Hasil dan Analisis \\ 3.1. Round Trip Delay (RTD)}

Round Trip Delay atau RTD merupakan penjumlahan dari dua jenis delay, yaitu delay yang dialami paket data dan delay ACK yang dihasilkan protokol TCP. Paket data maupun paket ACK terdiri dari delay transmisi dan delay propagasi. Tabel 2 menunjukkan nilai Round Trip Delay jaringan metro ethernet. 
Tabel 2 Round trip delay seluruh link jaringan metro ethernet

\begin{tabular}{cccc}
\hline \multirow{2}{*}{ Link } & \multirow{2}{*}{ RTD $(\mathrm{ms})$} & \multicolumn{2}{c}{ Standarisasi } \\
\cline { 3 - 4 } & & PT. Telkom & ITU-T \\
\hline LBG $\rightarrow$ HGM & 0,3453 & $\sqrt{ }$ & $\sqrt{ }$ \\
HGM $\rightarrow$ LBG & 0,3429 & $\sqrt{ }$ & $\sqrt{ }$ \\
DGO $\rightarrow$ HGM & 0,3322 & $\sqrt{ }$ & $\sqrt{ }$ \\
HGM $\rightarrow$ DGO & 0,3296 & $\sqrt{ }$ & $\sqrt{ }$ \\
CCD $\rightarrow$ DGO & 0,3250 & $\sqrt{ }$ & $\sqrt{ }$ \\
DGO $\rightarrow$ CCD & 0,3520 & $\sqrt{ }$ & $\sqrt{ }$ \\
LBG $\rightarrow$ CCD & 0,3636 & $\sqrt{ }$ & $\sqrt{ }$ \\
CCD $\rightarrow$ LBG & 0,3548 & $\sqrt{ }$ & $\sqrt{ }$ \\
LBG $\rightarrow$ TGA & 0,3530 & $\sqrt{ }$ & $\sqrt{ }$ \\
TGA $\rightarrow$ LBG & 0,3594 & $\sqrt{ }$ & $\sqrt{ }$ \\
TGA $\rightarrow$ RJW & 0,3386 & $\sqrt{ }$ & $\sqrt{ }$ \\
RJW $\rightarrow$ TGA & 0,3492 & $\sqrt{ }$ & $\sqrt{ }$ \\
LBG $\rightarrow$ RJW & 0,3776 & $\sqrt{ }$ & $\sqrt{ }$ \\
RJW $\rightarrow$ LBG & 0,3822 & $\sqrt{ }$ & $\sqrt{ }$ \\
LBG $\rightarrow$ UBR & 0,4203 & $\sqrt{ }$ & $\sqrt{ }$ \\
UBR $\rightarrow$ LBG & 0,4101 & $\sqrt{ }$ & $\sqrt{ }$ \\
UBR $\rightarrow$ CJA & 0,3254 & $\sqrt{ }$ & $\sqrt{ }$ \\
CJA $\rightarrow$ UBR & 0,3478 & $\sqrt{ }$ & $\sqrt{ }$ \\
CJA $\rightarrow$ TGG & 0,3640 & $\sqrt{ }$ & $\sqrt{ }$ \\
TGG $\rightarrow$ CJA & 0,3328 & $\sqrt{ }$ & $\sqrt{ }$ \\
LBG $\rightarrow$ TGG & 0,3456 & $\sqrt{ }$ \\
TGG $\rightarrow$ LBG & 0,3410 & $\sqrt{ }$ & $100 \%$ \\
\hline Persentase memenuhi & $100 \%$ & \multicolumn{2}{c}{$0,3542 \mathrm{~ms}$} \\
\hline Rata-rata RTD jaringan
\end{tabular}

Keterangan :

$\sqrt{ } \quad$ Memenuhi standarisasi

$\mathrm{x} \quad$ Tidak memenuhi standarisasi

Berdasarkan Tabel 2 mengenai Round Trip Delay, dapat diketahui bahwa keseluruhan link pada jaringan metro ethernet kota Bandung masih berada dibawah batas standarisasi dan memiliki performansi yang baik. Nilai Round Trip Delay jaringan memenuhi standarisasi PT. Telekomunikasi Indonesia, Tbk sebesar $<12$ ms maupun standarisasi ITU-T sebesar $<5 \mathrm{~ms}$. Nilai rata-rata Round Trip Delay jaringan metro ethernet sebesar $0,3542 \mathrm{~ms}$. Persentase link memenuhi standarisasi PT. Telekomunikasi Indonesia, Tbk sebesar 100\%, dan persentase link memenuhi standarisasi ITU-T (International Telecommunication Union Telecommunication Standardization Sector) sebesar $100 \%$.

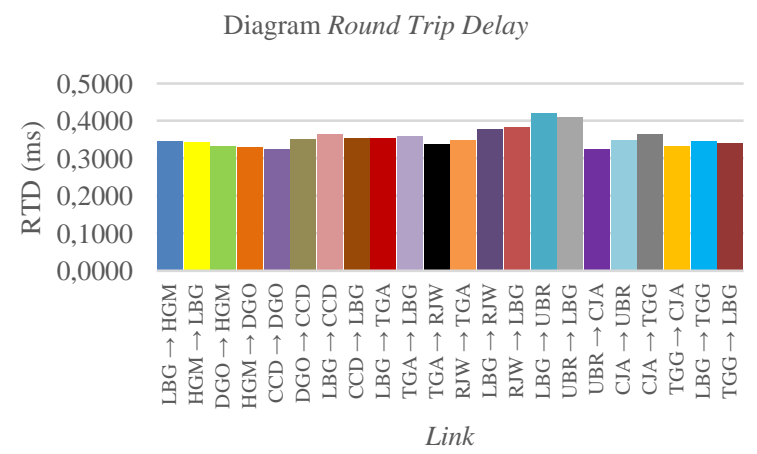

Gambar 3 Round trip delay seluruh link jaringan
Gambar 3 menunjukkan diagram perbandingan nilai RTD keseluruhan link jaringan metro ethernet. Berdasarkan Gambar 3, dapat diketahui bahwa link dengan nilai RTD tertinggi terdapat pada link $\mathrm{LBG} \rightarrow \mathrm{UBR}$ sebesar 0,4203 ms. Sedangkan, link dengan nilai round trip delay terendah adalah link $\mathrm{CCD} \rightarrow \mathrm{DGO}$ sebesar $0,3250 \mathrm{~ms}$. Hasil simulasi RTD menunjukkan bahwa keseluruhan link mampu melayani volume trafik yang terjadi, serta memiliki spesifikasi dan proses transmisi yang baik.

\subsection{Jitter}

Nilai metriks jitter pada penelitian mengacu pada statistik hasil simulasi pada OPNET Modeler. Metriks jitter telah ditentukan dalam objek node statistic sebelumnya. Hasil dari statistik tersebut diperoleh setelah simulasi dijalankan serta tidak perlu melakukan perhitungan lagi terhadap hasil akhir yang diperoleh. Parameter jitter dalam OPNET Modeler bernama variasi delay (end-to-end delay variation). Tabel 3 menunjukkan nilai jitter keseluruhan link jaringan metro ethernet.

\section{Tabel 3 Nilai jitter seluruh link jaringan metro ethernet}

\begin{tabular}{|c|c|c|c|}
\hline \multirow{2}{*}{ Link } & \multirow{2}{*}{ Jitter (ms) } & \multicolumn{2}{|c|}{ Standarisasi } \\
\hline & & PT. Telkom & ITU-T \\
\hline $\mathrm{LBG} \rightarrow \mathrm{HGM}$ & 0,1971 & $\sqrt{ }$ & $\sqrt{ }$ \\
\hline $\mathrm{HGM} \rightarrow \mathrm{LBG}$ & 0,1950 & $\sqrt{ }$ & $\sqrt{ }$ \\
\hline $\mathrm{DGO} \rightarrow \mathrm{HGM}$ & 0,2130 & $\sqrt{ }$ & $\sqrt{ }$ \\
\hline $\mathrm{HGM} \rightarrow \mathrm{DGO}$ & 0,2144 & $\sqrt{ }$ & $\sqrt{ }$ \\
\hline $\mathrm{CCD} \rightarrow \mathrm{DGO}$ & 0,2368 & $\sqrt{ }$ & $\sqrt{ }$ \\
\hline $\mathrm{DGO} \rightarrow \mathrm{CCD}$ & 0,2376 & $\sqrt{ }$ & $\sqrt{ }$ \\
\hline $\mathrm{LBG} \rightarrow \mathrm{CCD}$ & 0,2000 & $\sqrt{ }$ & $\sqrt{ }$ \\
\hline $\mathrm{CCD} \rightarrow \mathrm{LBG}$ & 0,2104 & $\sqrt{ }$ & $\sqrt{ }$ \\
\hline $\mathrm{LBG} \rightarrow \mathrm{TGA}$ & 0,2421 & $\sqrt{ }$ & $\sqrt{ }$ \\
\hline $\mathrm{TGA} \rightarrow \mathrm{LBG}$ & 0,2326 & $\sqrt{ }$ & $\sqrt{ }$ \\
\hline TGA $\rightarrow$ RJW & 0,2054 & $\sqrt{ }$ & $\sqrt{ }$ \\
\hline $\mathrm{RJW} \rightarrow \mathrm{TGA}$ & 0,2009 & $\sqrt{ }$ & $\sqrt{ }$ \\
\hline LBG $\rightarrow$ RJW & 0,2296 & $\sqrt{ }$ & $\sqrt{ }$ \\
\hline $\mathrm{RJW} \rightarrow \mathrm{LBG}$ & 0,2249 & $\sqrt{ }$ & $\sqrt{ }$ \\
\hline LBG $\rightarrow$ UBR & 0,2009 & $\sqrt{ }$ & $\sqrt{ }$ \\
\hline UBR $\rightarrow$ LBG & 0,1978 & $\sqrt{ }$ & $\sqrt{ }$ \\
\hline UBR $\rightarrow$ CJA & 0,2036 & $\sqrt{ }$ & $\sqrt{ }$ \\
\hline $\mathrm{CJA} \rightarrow \mathrm{UBR}$ & 0,1961 & $\sqrt{ }$ & $\sqrt{ }$ \\
\hline $\mathrm{CJA} \rightarrow \mathrm{TGG}$ & 0,2260 & $\sqrt{ }$ & $\sqrt{ }$ \\
\hline TGG $\rightarrow$ CJA & 0,2321 & $\sqrt{ }$ & $\sqrt{ }$ \\
\hline $\mathrm{LBG} \rightarrow \mathrm{TGG}$ & 0,2267 & $\sqrt{ }$ & $\sqrt{ }$ \\
\hline TGG $\rightarrow$ LBG & 0,2263 & $\sqrt{ }$ & $\sqrt{ }$ \\
\hline \multicolumn{2}{|c|}{ Persentase memenuhi } & $100 \%$ & $100 \%$ \\
\hline \multicolumn{2}{|c|}{ Rata-rata jitter } & \multicolumn{2}{|c|}{0,2159} \\
\hline
\end{tabular}

Keterangan:

$\begin{array}{ll}\sqrt{ } & \text { Memenuhi standarisasi } \\ \mathrm{x} & \text { Tidak memenuhi standarisasi }\end{array}$

Berdasarkan Tabel 3 mengenai variasi delay atau jitter, dapat diketahui keseluruhan link pada jaringan metro ethernet kota Bandung masih berada dibawah batas standarisasi dan memiliki performansi yang baik. Nilai jitter jaringan memenuhi standarisasi standarisasi PT. Telekomunikasi Indonesia, Tbk sebesar <10 ms maupun standarisasi ITU-T sebesar $<1 \mathrm{~ms}$. Nilai rata-rata jitter jaringan metro ethernet sebesar $0,2159 \mathrm{~ms}$. Persentase 
link memenuhi standarisasi PT. Telekomunikasi Indonesia, Tbk sebesar 100\%, dan persentase link memenuhi standarisasi ITU-T sebesar $100 \%$.

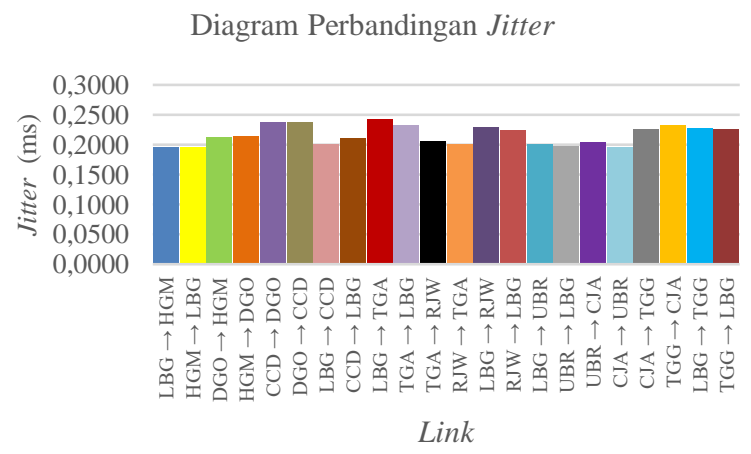

\section{Gambar 4 Round trip delay seluruh link jaringan}

Gambar 4 menunjukkan diagram perbandingan nilai variasi delay atau jitter seluruh link jaringan metro ethernet. Berdasarkan Gambar 3.2, dapat diketahui bahwa link dengan nilai jitter tertinggi terdapat pada link LBG $\rightarrow$ TGA sebesar 0,2421 ms. Sedangkan, link dengan nilai jitter terendah terdapat pada link $\mathrm{HGM} \rightarrow \mathrm{LBG}$ sebesar 0,1950 ms.

\subsection{Packet Loss}

Tabel 4 Nilai packet loss seluruh link jaringan metro ethernet

\begin{tabular}{cccc}
\hline \multirow{2}{*}{ Link } & \multirow{2}{*}{ Packet Loss $(\%)$} & \multicolumn{2}{c}{ Standarisasi } \\
\cline { 2 - 4 } & 0,000280 & PT. Telkom & ITU-T \\
\hline LBG $\leftrightarrow$ HGM & 0,000472 & $\sqrt{ }$ & $\sqrt{ }$ \\
HGM $\leftrightarrow$ DGO & 0,000449 & $\sqrt{ }$ & $\sqrt{ }$ \\
DGO $\leftrightarrow$ CCD & 0,000372 & $\sqrt{ }$ & $\sqrt{ }$ \\
LBG $\leftrightarrow$ CCD & 0,000344 & $\sqrt{ }$ & $\sqrt{ }$ \\
LBG $\leftrightarrow$ TGA & 0,000525 & $\sqrt{ }$ & $\sqrt{ }$ \\
TGA $\leftrightarrow$ RJW & 0,000153 & $\sqrt{ }$ & $\sqrt{ }$ \\
LBG $\leftrightarrow$ RJW & 0,000378 & $\sqrt{ }$ & $\sqrt{ }$ \\
LBG $\leftrightarrow$ UBR & 0,000501 & $\sqrt{ }$ & $\sqrt{ }$ \\
UBR $\leftrightarrow$ CJA & 0,000872 & $\sqrt{ }$ & $\sqrt{ }$ \\
CJA $\leftrightarrow$ TGG & 0,002093 & $\sqrt{ }$ \\
LBG $\leftrightarrow$ TGG & \multicolumn{2}{c}{$0.000585 \%$} \\
\hline \multicolumn{2}{c}{ Persentase memenuhi }
\end{tabular}

Keterangan :

$\begin{array}{ll}\sqrt{ } & \text { Memenuhi standarisasi } \\ \mathrm{x} & \text { Tidak memenuhi standarisasi }\end{array}$

Nilai metriks packet loss pada penelitian ini mengacu pada statistik hasil simulasi pada OPNET Modeler. Metriks packet loss telah ditentukan dalam objek link statistic sebelumnya. Hasil dari statistik tersebut diperoleh setelah simulasi dijalankan serta tidak perlu melakukan perhitungan lagi terhadap hasil akhir yang diperoleh. Parameter jitter dalam OPNET Modeler bernama variasi packet loss ratio. Tabel 4 menunjukkan nilai packet loss jaringan metro ethernet.

Berdasarkan Tabel 4, dapat diketahui bahwa 100\% link jaringan masih berada dibawah standarisasi packet loss PT. Telekomunikasi Indonesia, Tbk sebesar $<0,20 \%$ dan $88,89 \%$ link jaringan masih berada di bawah standarisasi packet loss ITU-T sebesat $<0,001 \%$. Nilai rata-rata packet loss jaringan metro ethernet sebesar $0,000585 \%$.

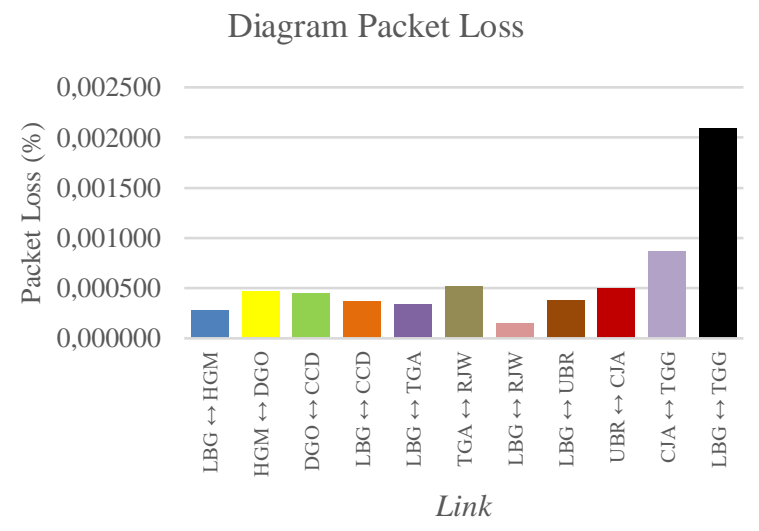

Gambar 5 Packet loss seluruh link jaringan

Gambar 5 menunjukkan diagram perbandingan nilai packet loss seluruh link jaringan metro ethernet. Berdasarkan Gambar 5, dapat diketahui bahwa link dengan nilai packet loss tertinggi terdapat pada link LBG $\leftrightarrow$ TGG sebesar 0,002093\%. Sedangkan, link dengan nilai packet loss terendah terdapat pada link $\mathrm{LBG} \leftrightarrow \mathrm{RJW}$ sebesar $0,000153 \%$.

\subsection{Utilisasi Link}

Tabel 5. Perbandingan nilai packet loss seluruh link jaringan metro ethernet

\begin{tabular}{cccc}
\hline \multirow{2}{*}{ Link } & \multicolumn{2}{c}{ Utilisasi (\%) } & \multirow{2}{*}{ Selisih (\%) } \\
\cline { 2 - 3 } & \multicolumn{1}{c}{ Simulasi } & Perhitungan & \\
\hline LBG $\leftrightarrow$ HGM & 48,4234 & 48.4221 & 0.0013 \\
HGM $\leftrightarrow$ DGO & 34,3746 & 34,3283 & 0.0463 \\
DGO $\leftrightarrow$ CCD & 45,3510 & 45,3386 & 0.0124 \\
LBG $\leftrightarrow$ CCD & 48,4699 & 48,4540 & 0.0159 \\
LBG $\leftrightarrow$ TGA & 45,6123 & 45,5367 & 0.0756 \\
TGA $\leftrightarrow$ RJW & 38,1176 & 38,1000 & 0.0176 \\
LBG $\leftrightarrow$ RJW & 52,9631 & 52,9206 & 0.0425 \\
LBG $\leftrightarrow$ UBR & 48,7819 & 48,7671 & 0.0148 \\
UBR $\leftrightarrow$ CJA & 29,7614 & 29,8037 & 0.0423 \\
CJA $\leftrightarrow$ TGG & 41,5246 & 41,5254 & 0.0008 \\
LBG $\leftrightarrow$ TGG & 45,9706 & 45,9641 & 0.0065 \\
\hline Rata-rata & 43,5773 & 43,5601 & 0,0173 \\
\hline
\end{tabular}

Nilai metriks utilisasi pada penelitian ini mengacu pada statistik hasil simulasi pada OPNET Modeler. Metriks utilisasi telah ditentukan dalam objek link statistic sebelumnya. Hasil dari statistik tersebut diperoleh setelah 
simulasi dijalankan serta tidak perlu melakukan perhitungan lagi terhadap hasil akhir yang diperoleh.

\subsection{Utilisasi Link}

Tabel 5 Perbandingan nilai packet loss seluruh link jaringan metro ethernet

\begin{tabular}{cccc}
\hline \multirow{2}{*}{ Link } & \multicolumn{2}{c}{ Utilisasi (\%) } & \multirow{2}{*}{ Selisih (\%) } \\
\cline { 2 - 3 } & Simulasi & Perhitungan & \\
\hline LBG $\leftrightarrow$ HGM & 48,4234 & 48,4221 & 0.0013 \\
HGM $\leftrightarrow$ DGO & 34,3746 & 34,3283 & 0.0463 \\
DGO $\leftrightarrow$ CCD & 45,3510 & 45,3386 & 0.0124 \\
LBG $\leftrightarrow$ CCD & 48,4699 & 48,4540 & 0.0159 \\
LBG $\leftrightarrow$ TGA & 45,6123 & 45,5367 & 0.0756 \\
TGA $\leftrightarrow$ RJW & 38,1176 & 38,1000 & 0.0176 \\
LBG $\leftrightarrow$ RJW & 52,9631 & 52,9206 & 0.0425 \\
LBG $\leftrightarrow$ UBR & 48,7819 & 48,7671 & 0.0148 \\
UBR $\leftrightarrow$ CJA & 29,7614 & 29,8037 & 0.0423 \\
CJA $\leftrightarrow$ TGG & 41,5246 & 41,5254 & 0.0008 \\
LBG $\leftrightarrow$ TGG & 45,9706 & 45,9641 & 0.0065 \\
\hline Rata-rata & 43,5773 & 43,5601 & 0,0173
\end{tabular}

Berdasarkan Tabel 5 dapat dilihat bahwa utilisasi link hasil simulasi dan hasil simulasi link hasil perhitungan memiliki nilai yang mendekati. Selisih nilai utilisasi terbesar terdapat pada link LBG $\leftrightarrow$ TGA sebesar 0,0756\%, sedangkan selisih terkecil terdapat pada link CJA $\leftrightarrow$ TGG sebesar $0,0008 \%$. Selisih ini terjadi karena nilai utilisasi simulasi merupakan nilai rata-rata dari nilai utilisasi link antar dua node. Sehingga, terjadi perbedaan ketelitian antara hasil simulasi dan hasil perhitungan. Nilai rata-rata utilisasi jaringan sebesar 43,5773. Nilai utilisasi jaringan secara keseluruhan berada di bawah 55\%, hal ini menunjukkan bahwa link mampu melayani volume trafik yang terjadi, serta memiliki spesifikasi dan proses transmisi yang baik. Sehingga, jaringan belum perlu memerlukan upgrade atau menambah kapasitas untuk dapat melayani trafik yang terjadi.

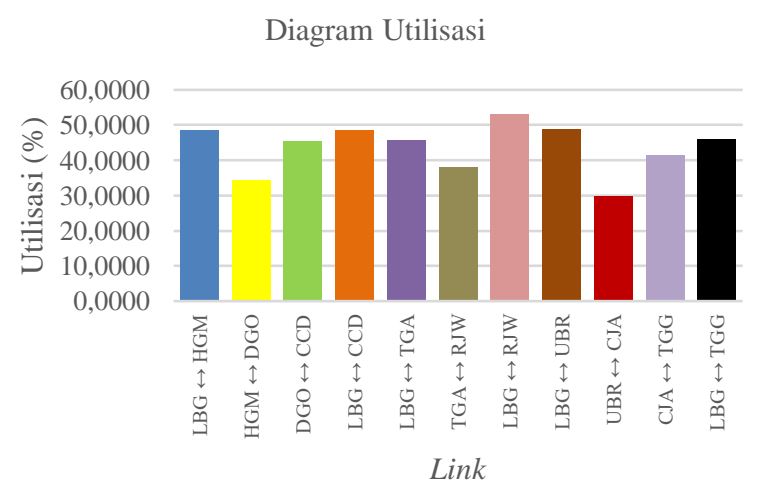

\section{Gambar 6 Utilisasi seluruh link jaringan}

Gambar 6 menunjukkan perbandingan nilai utilisasi seluruh link jaringan metro ethernet. Berdasarkan Gambar 6, dapat diketahui bahwa nilai utilisasi tertinggi terdapat pada link $\mathrm{LBG} \leftrightarrow \mathrm{RJW}$ sebesar 52,9631. Sedangkan, nilai utilisasi terendah terdapat pada link UBR CJA sebesar 29,7614 .

\subsection{Waktu Konvergensi}

Pada penelitian ini, terdapat tiga skenario keadaan jaringan metro ethernet. Skenario tersebut antara lain, link dalam keadaan normal, satu link putus, dan dua link putus. Tabel 6 menunjukkan hasil simulasi waktu konvergensi jaringan metro ethernet.

Tabel 6 Waktu konvergensi seluruh node jaringan metro ethernet

\begin{tabular}{cccc}
\hline \multirow{2}{*}{ Node } & \multicolumn{3}{c}{ Waktu Konvergensi (s) } \\
\cline { 2 - 4 } ME_LBG & Normal & 1 Link Putus & 2 Link Putus \\
\hline ME_HGM & 15 & 15 & 15 \\
ME_DGO & 15 & 15 & 15 \\
ME_CCD & 15 & 15 & 15 \\
ME_UBR & 15 & 15 & 15 \\
ME_CJA & 15 & 15 & 15 \\
ME_TGG & 15 & 15 & 15 \\
ME_TGA & 15 & 15 & 15 \\
ME_RJW & 15 & 15 & 15 \\
\hline Rata-Rata & 15 & 15 & 15 \\
\hline
\end{tabular}

Tabel 6 menunjukkan waktu konvergensi setiap node pada jaringan metro ethernet dengan menggunakan protokol routing OSPF. Berdasarkan Tabel 6 dapat diketahui bahwa waktu konvergensi node adalah $15 \mathrm{~s}$. Kemudian, rata-rata waktu konvergensi pada jaringan adalah $15 \mathrm{~s}$.

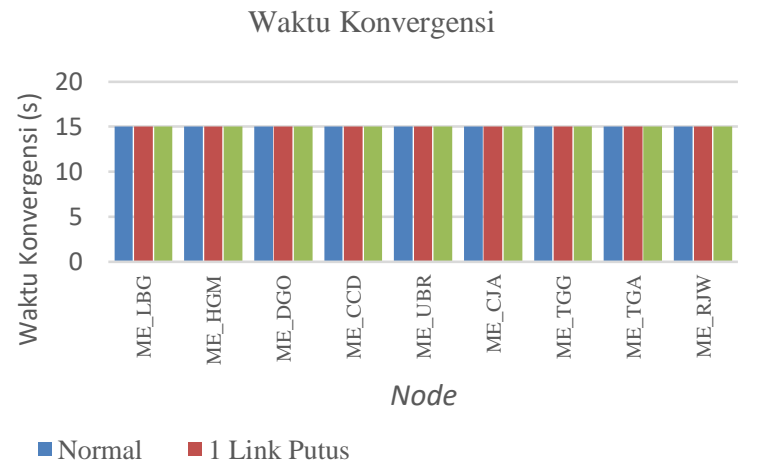

\section{Gambar 7 Waktu konvergensi jaringan}

Gambar 7 menunjukkan perbandingan waktu konvergensi jaringan dalam keadaan normal, satu link terputus, dan dua link terputus. Berdasarkan Gambar 7 dapat diketahui bahwa baik dalam keadaan normal, satu link terputus, maupun dua link terputus, waktu konvergensi jaringan tetap yaitu $15 \mathrm{~s}$. Hal ini dapat disebabkan karena besarnya jaringan tidak berubah, tidak terdapat node yang ditambahkan dalam jaringan. Sehingga, waktu konvergensi yan diperlukan jaringan pun juga tetap. 


\section{Kesimpulan}

Berdasarkan hasil simulasi yang telah dilakukan, dapat diambil kesimpulan antara lain. Pengukuran performansi jaringan untuk metriks round trip delay (RTD) menunjukkan bahwa $100 \%$ link memenuhi standarisasi PT. Telekomunikasi Indonesia sebesar $<12 \mathrm{~ms}$ dan standarisasi ITU-T sebesar $<5 \mathrm{~ms}$. Nilai rata-rata RTD jaringan metro ethernet sebesar 0,3542 ms. Pengukuran performansi jaringan untuk metriks jitter menunjukkan bahwa $100 \%$ link memenuhi standarisasi PT. Telekomunikasi Indonesia sebesar $<10 \mathrm{~ms}$ dan standarisasi ITU-T sebesar $<1 \mathrm{~ms}$. Nilai rata-rata jitter jaringan metro ethernet sebesar 0,2159 ms. Pengukuran performansi jaringan untuk metriks packet loss menunjukkan bahwa $100 \%$ link memenuhi standarisasi PT. Telekomunikasi Indonesia sebesar $<0,20 \%$ dan $88,89 \%$ link memenuhi standarisasi ITU-T sebesar $<0,001 \%$. Nilai rata-rata packet loss jaringan metro ethernet sebesar $0.000585 \%$. Nilai utilisasi tertinggi terdapat pada link LBG $\leftrightarrow$ RJW sebesar 52,9631. Sedangkan, nilai utilisasi terendah terdapat pada link UBR↔CJA sebesar 29,7614. Pengukuran performansi jaringan untuk metriks waktu konvergensi menunjukkan bahwa dalam tiga skenario diperoleh waktu konvergensi yang sama, yaitu 15 detik.

\section{Referensi}

[1]. Anonim. "Kota Bandung dalam Angka 2017". Badan Pusat Statistik Kota Bandung. 2017.

[2]. S. Y. Pratama, "Analisis Performansi Link Pada Jaringan Metro Ethernet Regional Jawa Tengah Menggunakan Simulator OPNET 14.5." Laporan Penelitian Teknik Elektro Universitas Diponegoro. 2017.
[3]. A.Tris Susilo, Analisa Implementasi dan Quality of Service Metro Ethernet pada Group Customer Solution PT. Indosat. Program Studi Teknik Elektro Fakultas Teknik Universitas Mercu Buana, 2012.

[4]. D. T. Putri, T. Juhana, and S. Haryadi, "DWDM system design: DIY-Semarang-Surakarta ring," Proc. - ICWT 2016 2nd Int. Conf. Wirel. Telemat. 2016, pp. 111-116, 2017.

[5]. PT Telekomunikasi Indonesia, Tbk. Kebijakan Pengelolaan Infrastruktur Infocom Divisi Infratel KV.85/TK000/DIT-050/2009. Semarang. 2009.

[6]. EXFO Inc., "EtherSAM : The New Standard In Ethernet Service Testing,"

[7]. Manalu, Donda Maria Tiurma. Analisis Perancangan Jaringan Serat Optik DWDM (Dense Wavelength Division Multiplexing) Untuk Link Medan - Langsa. Laporan Penelitian Teknik Elektro Universitas Sumatra Utara.

2012.

[8]. I. Technology, "Evaluation Study for Delay and Link Utilization with the New-Additive Increase Multiplicative Decrease Congestion Avoidance and Control Algorithm," pp. 1-15.

[9]. D. Edi, "Kajian Algoritma Routing Dalam Jaringan Komputer," J. Inform. UKM, vol. II, no. 3, pp. 47-55.

[10]. T. Informatika, I. Sains, and T. Akprind, "Jurnal JARKOM Vol . 4 No . 1 Desember 2016 ISSN : 23386313 IMPLEMENTASI ROUTING OPEN SHORTEST PATH FIRST ( OSPF ) MELALUI TUNNEL OPEN VPN Jurnal JARKOM Vol . 4 No . 1 Desember 2016 ISSN : 2338-6313," vol. 4, no. 1, pp. 62-70, 2016.

[11]. H. A. Musril, "ANALISIS UNJUK KERJA RIPv2 DAN EIGRP DALAM DYNAMIC ROUTING PROTOCOL THE PERFORMANCE ANALYSIS OF RIPv2 AND EIGRP ON," J. Elektro Telekomun. Terap. Desember, pp. 116-124, 2015. 